\title{
Effect of endotoxin treatment on prostaglandin metabolism by rabbit uterus and oviduct
}

\author{
M. J. K. Harper, R. R. Bodkhe* and W. E. Friedrichs \\ Center for Research and Training in Reproductive Biology, Department of Obstetrics and \\ Gynecology, The University of Texas Health Science Center at San Antonio, \\ 7703 Floyd Curl Drive, San Antonio, Texas 78284, U.S.A.
}

\begin{abstract}
Summary. Metabolism of PGE-2 and PGF-2 $\alpha$ by cytosolic fractions (100 $000 \mathrm{~g}$ supernatant) of the uterus, oviduct and lung of rabbits treated with hCG and endotoxin $(20 \mu \mathrm{g} / \mathrm{kg})$ was measured. Endotoxin caused immediate decreases in metabolism of both PGs by uterus at $1 \mathrm{~h}$, and these decreases became significant at 2 $\mathrm{h}$ for PGE-2 and $6 \mathrm{~h}$ for PGF-2 $\alpha$. The metabolism of both PGs remained depressed throughout the $24 \mathrm{~h}$ study. Metabolism by oviduct tissue differed in that at $1 \mathrm{~h}$ metabolism of both PGs increased but then remained depressed between 2 and $24 \mathrm{~h}$. Metabolism of PGs by lung also showed a different pattern: that of PGE-2 was depressed only briefly (at $2 \mathrm{~h}$ ), while that of PGF- $2 \alpha$ was consistently depressed between 2 and $24 \mathrm{~h}$. Pre-treatment with hCG did not affect the response: tissues from animals killed $6 \mathrm{~h}$ after endotoxin but not given $\mathrm{hCG}$ responded like those from animals treated with endotoxin $24 \mathrm{~h}$ after hCG and killed $6 \mathrm{~h}$ later. Much of the increased PG levels in venous drainage after endotoxin treatment can be explained by depressed ability of cells to metabolize PGs.
\end{abstract}

\section{Introduction}

Endotoxin causes accelerated transport of ova through the rabbit oviduct (Harper, Valenzuela \& Hodgson, 1978). This action occurs within $4 \mathrm{~h}$ when the endotoxin is administered at $24 \mathrm{~h}$ after an ovulating injection of human chorionic gonadotrophin (hCG), is associated with elevated levels of prostaglandins $\mathrm{F}$ and $\mathrm{E}$ in uterine vein blood, and can be prevented by concomitant administration of indomethacin, a known prostaglandin (PG) synthesis inhibitor. There is evidence from studies with other tissues that endotoxin does not inhibit the PG synthetase system to any great degree (Herman \& Vane, 1975a, b; Blackwell, Flower, Parsons \& Vane, 1975a; Blackwell, Flower \& Herman, 1976).

Studies with protein synthesis inhibitors suggest that the PG synthetase is a stable complex of enzymes (Blackwell et al., 1975a; Blackwell, Flower \& Vane, 1975b). By contrast, the PG dehydrogenase, which catalyses the oxidation of PGs at the C-15 alcohol, the initial step in the metabolic degradation of PGs (Änggärd \& Samuelsson, 1964), is a short-lived enzyme whose replacement depends on de-novo protein synthesis (Blackwell et al., 1975a, b).

Endotoxin given in vivo to rabbits increases release of PGs from isolated jejunum (Herman \& Vane, 1975a) and homogenates of lung, jejunum, spleen and kidney (Herman \& Vane, 1975b), and elevates PG levels in uterine vein blood (Harper et al., 1978). Endotoxin also reduces metabolism of PGs in rat kidney and lung (Nakano \& Prancan, 1973) and rabbit jejunum and lung (Blackwell et al., 1976).

Consequently, the present studies were done to determine whether the increased levels of PGs seen in uterine vein blood following endotoxin administration could be accounted for by depressed metabolism of PGs by uterine and oviduct tissue.

* Present address: Department of Biochemistry, Government Medical College, Jabalpur, M.P., India. 


\section{Materials and Methods}

\section{Animals}

Mature female New Zealand White rabbits weighing $3.0-4.5 \mathrm{~kg}$ and over 6 months old were caged individually in a controlled environment ( $14 \mathrm{~h}$ light $/ 24 \mathrm{~h}$ dark). Water and food were supplied ad libitum. Pseudopregnancy was induced by the intravenous administration of 100 i.u. hCG (APL: Ayerst, New York) 1 month before use to ensure good development of the reproductive tract.

A second injection of 100 i.u. hCG was given to each animal at time zero. Groups of animals were then killed 24, 30 and $48 \mathrm{~h}$ later by an overdose of sodium pentobarbitone (Diabutal: Diamond Labs, Des Moines, Iowa). Other groups received endotoxin derived from Salmonella enteritidis (Boivin: Sigma Chemical Co., St Louis, Missouri). The endotoxin $(20 \mu \mathrm{g} / \mathrm{kg})$ was given intravenously $24 \mathrm{~h}$ after hCG and the rabbits were killed 1, 2, 6, 12 and $24 \mathrm{~h}$ later.

Two groups of oestrous animals were also studied. One of these groups was killed without other treatment, while the other received endotoxin and was killed $6 \mathrm{~h}$ later.

\section{Chemicals and preparation of enzyme fraction}

These were exactly as described by Bodkhe \& Harper (1979).

\section{Incubation procedures and assay for metabolism}

The incubation conditions and assays were as described by Bodkhe \& Harper (1979). The incubation mixture contained $2 \mathrm{mM}-\mathrm{NAD}^{+}, 1 \mu \mathrm{g}$ of the appropriate unlabelled PG, about 40000 c.p.m. of the appropriate labelled PG (representing approximately 126 pg PGE-2 and 85 pg PGF- $2 \alpha$ ), and a $1 \mathrm{ml}$ of the enzyme preparation in $44 \mathrm{mM}$-Tris- $\mathrm{HCl}$ buffer containing various concentrations of protein depending on the tissue. The incubations, in a Dubnoff metabolic shaker, were at $37^{\circ} \mathrm{C}$ for $60 \mathrm{~min}$ to study PGF-2 $\alpha$ dehydrogenase and for $30 \mathrm{~min}$ to study PGE2 dehydrogenase.

The results of the ratiometric assay for PGE- 2 and PGF- $2 \alpha$ metabolism were corrected for procedural losses, non-enzymic conversion (use of boiled cytosol) and loss of one tritium atom during metabolism and then calculated as $\mathrm{pmol} / \mathrm{mg}$ cytosolic protein. Statistical comparisons were effected by analyses of variance, followed by a Student-Newman-Kuels test (Sokal \& Rohlf, 1969) or linear regression analysis (Texas Instruments Statistics library Program ST108).

\section{Results}

\section{Effect of endotoxin given to 1-day pseudopregnant rabbits}

Table 1 shows the amounts of PGs metabolized by lung, uterus and oviduct and the amounts of products formed when endotoxin was given at $24 \mathrm{~h}$ after an injection of hCG.

Lung. PGE-2 metabolism was not significantly depressed at any time from the level at $0 \mathrm{~h}$ (control group $24 \mathrm{~h}$ after hCG), but the $2 \mathrm{~h}$ value was different from that at $1 \mathrm{~h}$ after endotoxin treatment. The amount of the 15-keto metabolite that was not converted to the 13,14-dihydro15-keto metabolite was small and did not vary. The production of the 13,14-dihydro-15-keto metabolite followed a trend similar to the metabolism of PGE-2. By contrast, metabolism of PGF- $2 \alpha$ was very greatly inhibited within $2 \mathrm{~h}$ and was still depressed by $24 \mathrm{~h}$ after endotoxin injection. The amount of 15 -keto PGF- $2 \alpha$ remaining was low, while the amount of the 13,14 dihydro-15-keto metabolite produced closely followed the amount of PGF-2 $\alpha$ metabolized.

Uterus. Metabolism of PGE-2 by the uterus was decreased within $1 \mathrm{~h}$ and significantly so by $2 \mathrm{~h}$. There was increased metabolism after the low value at $4 \mathrm{~h}$, but the values were significantly lower than those for the 0 and $6 \mathrm{~h}$ controls; only the $4 \mathrm{~h}$ value was different from the $24 \mathrm{~h}$ 


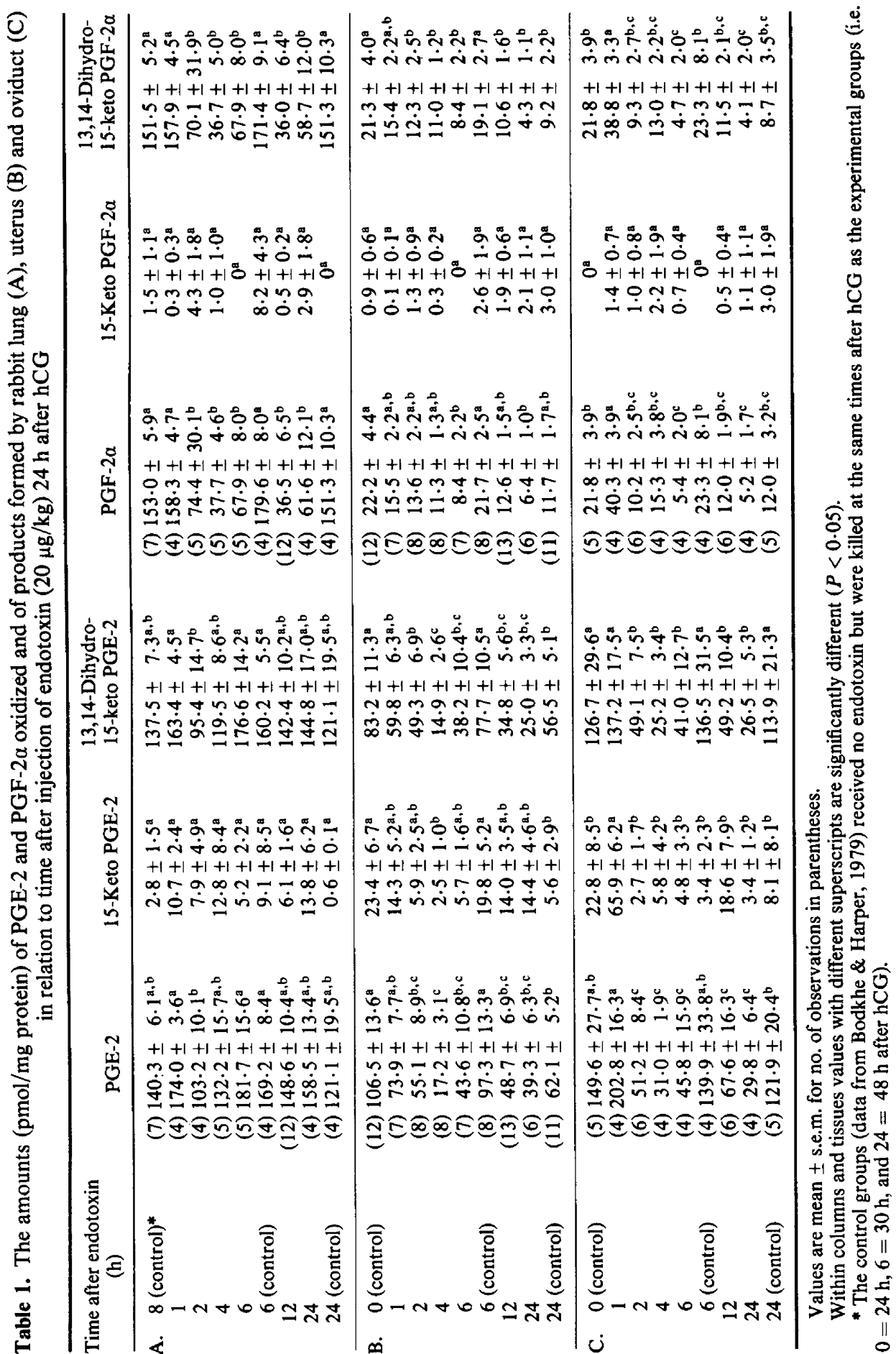


control. Approximately $10-20 \%$ of the products formed from metabolism of PGE-2 remained in the 15-keto form and the pattern of metabolite production reflected the amounts of PGE-2 metabolized, i.e. as less PGE-2 was metabolized, less product was formed.

The metabolism of PGF-2 $\alpha$ by the uterus was much slower than that of PGE-2, only about $10 \%$ being metabolized in the same time period. Consequently, although the changes in PGF-2 $\alpha$ metabolism were similar, significant depression of metabolism was only seen at $6 \mathrm{~h}$. Nearly all the product was in the 13,14-dihydro-15-keto form.

Oviduct. The changes in the oviduct were different from those in the uterus. There was no reduction of metabolism at $1 \mathrm{~h}$ for either PG and the amount of PGF-2a metabolized was

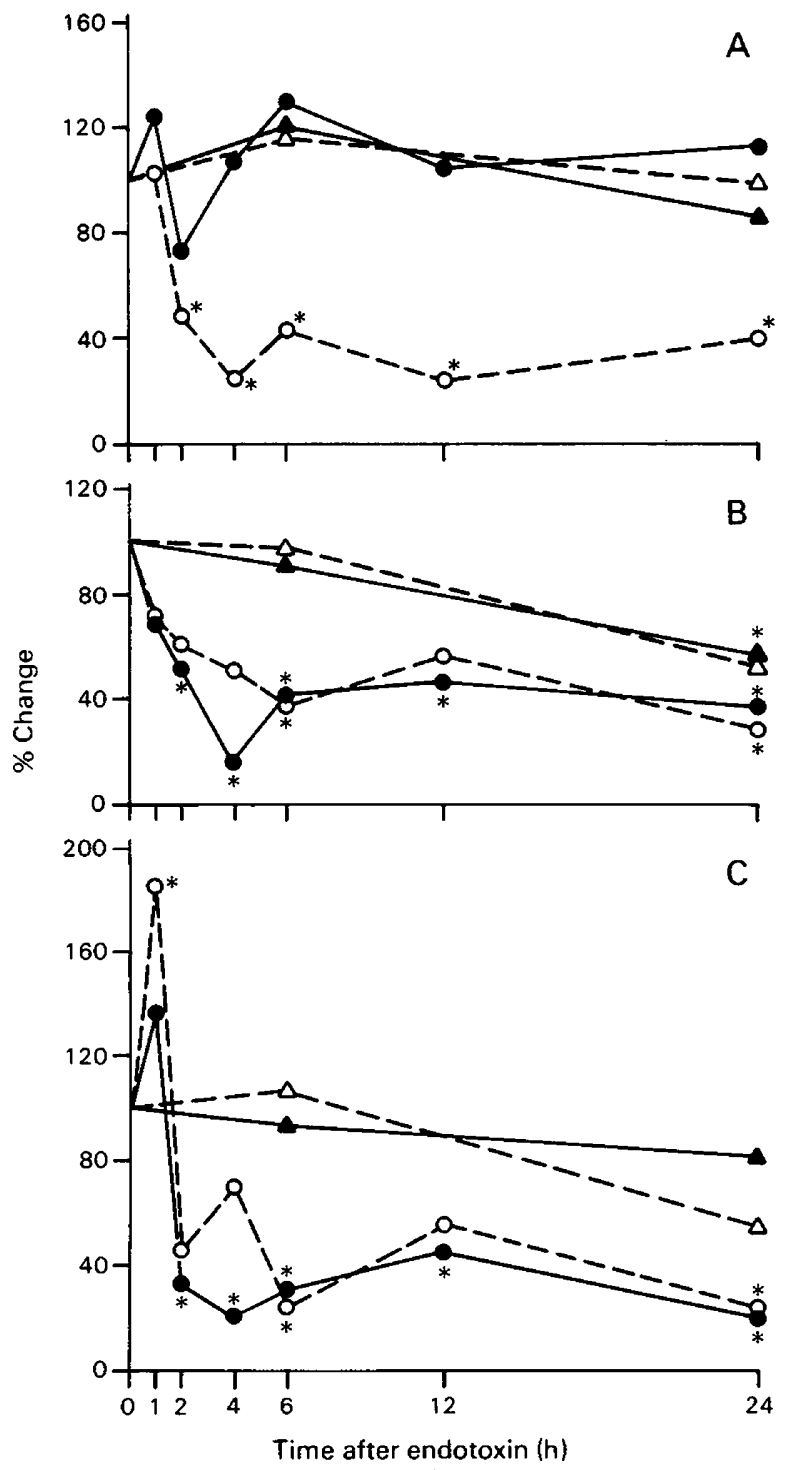

Text-fig. 1. Percentage change from control value (100\%) of metabolism of PGE-2 and PGF-2 $\alpha$ by rabbit lung (A), uterus (B) and oviduct (C) cytosol. Values significantly different from those of the relative control at $24 \mathrm{~h}$ after hCG $(P<0.05)$ are indicated by an asterisk. $\triangle$, PGE-2 control; $\triangle$, PGF-2 $\alpha$ control (data from Bodkhe \& Harper, 1979); O, PGE-2 + endotoxin; O, PGF- $2 \alpha+$ endotoxin. 
actually significantly greater than that of the $0 \mathrm{~h}$ control. The change in PGE-2 metabolism was due to a greatly increased production of the 15 -keto metabolite, while all the additional metabolism of PGF-2 $\alpha$ was represented by the 13,14-dihydro-15-keto metabolite. By $2 \mathrm{~h}$, there was a dramatic depression of PG metabolism to levels below control (PGE-2) or the value at $1 \mathrm{~h}$ (PGF-2 $\alpha$ ). Metabolism of PGE-2 remained depressed at the same level until $24 \mathrm{~h}$, but PGF-2 $\alpha$ metabolism was only significantly reduced from control values at $6 \mathrm{~h}$. Apart from the increased amount of 15-keto-PGE-2 measured at $1 \mathrm{~h}$ the amounts of the 15-keto metabolite did not vary. Formation of 13,14-dihydro-15-keto PGE-2 was depressed from control values at all times except for the $1 \mathrm{~h}$ group, but formation of 13,14-dihydro-15-keto PGF-2 $\alpha$ was, significantly depressed only at $6 \mathrm{~h}$.

\section{Percentage changes}

Since the amounts of the 2 PGs metabolized by the uterus and oviduct differed greatly, the percentage changes from the $0 \mathrm{~h}$ control value (represented as $100 \%$ ) are shown in Text-fig. 1 .

With the exception of the lung, it can be seen that the decreases of PGE-2 and PGF-2 $\alpha$ were very similar. There was, however, an indication with both the uterine and oviduct tissue that at the 2 and $4 \mathrm{~h}$ times, PGE-2 metabolism was more depressed than that of PGF- $2 \alpha$. The increased metabolism of PGF-2 $\alpha$ by the oviduct at $1 \mathrm{~h}$ compared to that of PGE-2 might alter the ratio of PGs in the smooth muscle cells at this time.

\section{Effect of endotoxin given to oestrous rabbits}

Since metabolism of PGs by reproductive tissue is decreased after administration of hCG (Bodkhe \& Harper, 1979), we examined whether the above results were due to the rabbits being pseudopregnant.

The results from oestrous animals given $20 \mu \mathrm{g}$ endotoxin $/ \mathrm{kg}$ and killed $6 \mathrm{~h}$ later (Table 2) were very similar to those in Table 1 for animals given hCG $24 \mathrm{~h}$ before the endotoxin and killed $6 \mathrm{~h}$ after endotoxin. Prostaglandin metabolism was always decreased after endotoxin treatment and the differences were significant for lung and uterus but not for oviduct $(P<0.08)$, probably because of the small numbers/group. Since the amounts of PGs metabolized by tissues from oestrous rabbits were in general greater than those by tissues from 1-day pseudopregnant animals, the figures presented in Table 2 (with the exception of the lung) are greater than those shown in Table 1. However, the percentage changes from control during this $6 \mathrm{~h}$ period were very similar for uterus to those for animals killed $6 \mathrm{~h}$ after endotoxin and $30 \mathrm{~h}$ after hCG: the respective decreases were 54 and $55 \%$ for PGE-2 and 59 and $61 \%$ for PGF-2 $\alpha$. There was less correspondence for the percentage changes in lung metabolism $(-26$ and +7 for PGE- 2 and -77 and -62 for PGF-2 $\alpha$ ) and oviduct metabolism ( -53 and -67 for PGE-2 and -55 and -77 for PGF-2 $\alpha$ ).

\section{Discussion}

In previous experiments (Bodkhe \& Harper, 1979) we have shown that metabolism of PGE-2 and PGF- $2 \alpha$ by uterine and oviduct tissue is affected by the hormonal status of the rabbit. We now demonstrate that the PG-metabolizing activity of reproductive tissue is also greatly affected by endotoxin treatment. This is in agreement with the reported actions of endotoxin on metabolism of PGs by rabbit jejunum and lung (Blackwell et al., 1976) and by rat kidney and lung (Nakano \& Prancan, 1973).

We had previously shown that the actions of endotoxin in causing accelerated ovum transport when given to 1-day pseudopregnant rabbits were mediated by prostaglandin(s), since the effect could be blocked by indomethacin and was associated with increased levels of PGF- 


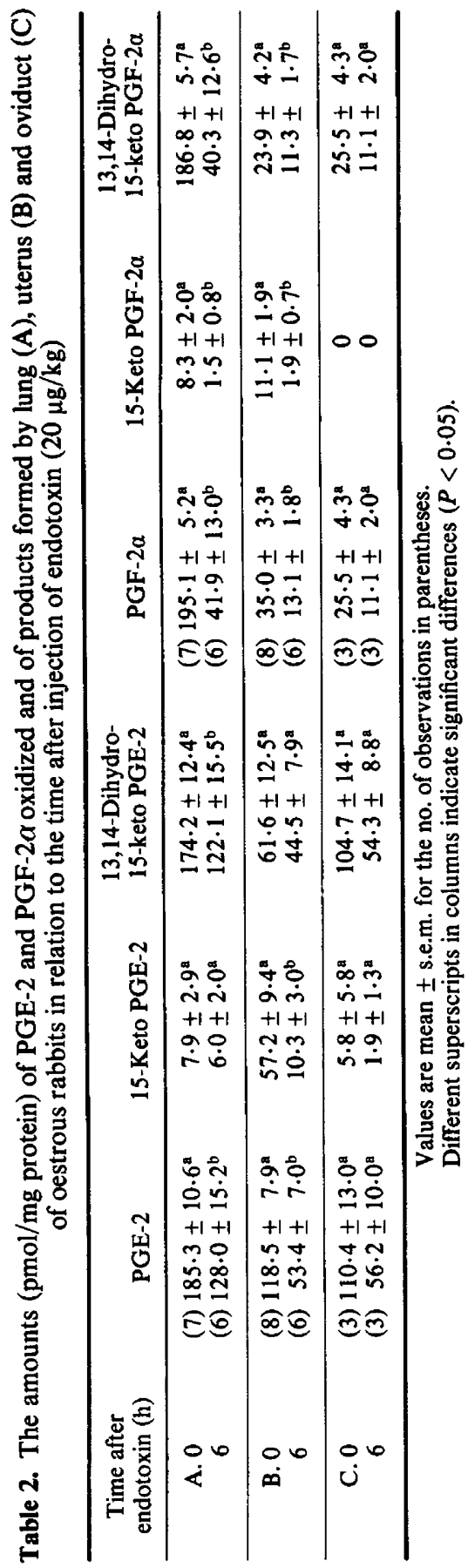


and PGE-like material in uterine venous blood (Harper et al., 1978). The appearance of these PGs in uterine vein blood correlated well with the action on ovum transport, i.e. ova were accelerated from the oviduct and uterus between 2 and $4 \mathrm{~h}$ after endotoxin injection, while the concentrations of PGE- and PGF-like material in uterine vein blood were elevated within 1 and $1.5 \mathrm{~h}$ respectively of endotoxin injection. The concentrations continued to rise up to $4 \mathrm{~h}$ and then reached a plateau lasting at least until $9 \mathrm{~h}$ (Harper $e t$ al., 1978). There is evidence that endotoxin (E. coli, 0111:B4) given intravenously causes increased accumulation of PGs in medium used for incubation of rabbit jejunum (Herman \& Vane, 1975a), but further studies showed that synthesis was not increased; rather there was a decrease in PG metabolism, thus permitting accumulation of greater concentrations in the incubation medium (Blackwell et al., 1976). In addition, Bhattacherjee \& Phylactos (1978) have provided evidence that endotoxin (Shigella sp.) given intravenously can inhibit rabbit kidney microsomal PG synthetase, although irisciliary processes were unaffected in the same rabbits. It may, therefore, be concluded that the increased accumulation of PGs in incubations in vitro after endotoxin given in vivo is simply a reflection of decreased metabolism of PGs. Thus, we supposed that increased levels of PGs in venous effluent following endotoxin treatment (Anderson, Jubicz, Tsagaris \& Kuida, 1975; Anderson, Tsagaris, Jubicz \& Kuida, 1975; Ramwell, Fletcher \& Flamenbaum, 1975; Herman \& Vane, 1976; Harper et al., 1978) might also be due to the known actions of endotoxin on PG metabolism.

In the present experiments, we observed that uterine metabolism of PGs was decreased within $1 \mathrm{~h}$ of endotoxin injection and continued to be further depressed until $6 \mathrm{~h}$, when the percentage changes from control were maximal. By contrast, metabolism of both PGE-2 and PGF- $2 \alpha$ by oviduct tissue was actually stimulated at $1 \mathrm{~h}$ before being depressed at $2 \mathrm{~h}$, but again maximal depression of metabolism was seen between 4 and $6 \mathrm{~h}$ after endotoxin. Uterine venous blood of the rabbit can carry a proportion of blood draining from the oviduct (Dickson, Waldhalm \& Amend, 1974), but in the experiments in which we measured PG levels following endotoxin injection we sampled from a venous branch draining only uterine tissue (Harper et al., 1978). Consequently, in the present experiments we might expect to have observed an initial depression of metabolism of PGE-2 followed slightly later by depression of PGF-2 $\alpha$ by uterine tissue. In fact, there was not a close degree of correspondence, but the acts of anaesthesia, laparotomy and cannulation of a uterine vein might be sufficient to distort the balance between various PGs and PG-like materials in the venous effluent. Nonetheless, it seems that most, if not all, the increased apparent production of PGs by reproductive, and probably other, tissues following endotoxin is due to decreased metabolism and not increased synthesis.

Given these facts, we may speculate that after endotoxin treatment the rabbit oviduct smooth muscle cells first experience decreased exposure to PGE-2, but more especially PGF-2 $\alpha$, thus disrupting the normal PGF dominant situation at oestrus. Microsomal preparations from oestrous rabbit oviducts make similar quantities of PGEs and PGFs (Valenzuela \& Harper, 1976), and yet PGF-2 $\alpha$ is metabolized only $10-20 \%$ as rapidly as PGE-2 (present study). Incubations of whole sections of ampulla or isthmus of $24 \mathrm{~h}$ rabbit oviduct for $60 \mathrm{~min}$ also give rise to approximately equal quantities of PGF (ampulla: $0.51 \pm 0.08$ and isthmus: $0.57 \pm 0.06$ $\mathrm{ng} / \mathrm{mg}$ protein $/ \mathrm{h}$ ) and of PGE (ampulla: $0.40 \pm 0.05$ and isthmus: $0.49 \pm 0.07 \mathrm{ng} / \mathrm{mg}$ protein/h) in the medium (Harper, Coons, Radicke, Hodgson \& Valenzuela, 1979; Harper, 1979). Thus the oviduct transports to the medium between 22 and $31 \mathrm{fmol} P G E$ or PGF/mg protein $/ \mathrm{min}$. These amounts are approximately 400-500 times less than was found in the medium when the microsomal fractions were used (Valenzuela \& Harper, 1976), and argue for the importance of an intracellular metabolic activity as a regulator of the amounts of PGs transported from the cells. Following disruption of PGF dominance by endotoxin administration, the oviduct is then exposed to greatly increased quantities of both PGEs and PGFs, especially Es during the 2nd to 4th hours (Text-fig. 1). PGEs normally relax and PGFs normally contract oviduct musculature (Spilman \& Harper, 1973), but when oviduct smooth musculature is 
exposed to both PGs together, the response depends greatly on the balance between the PGs and the previous exposure of the muscle cells to them (Hodgson, Harper \& Valenzuela, 1978). Further work will be needed to resolve the precise actions of PGs endogenously generated by endotoxin on the smooth muscle cells of the oviduct and uterus.

In the present studies the lung incubations were continued beyond an optimal time and hence the differences in metabolic pattern between PGE-2 and PGF- $2 \alpha$ cannot be regarded as conclusive. However, it may be significant that, despite the lengthy incubation metabolism of PGF- $2 \alpha$ by lung never returned to normal as did that of PGE-2. Consequently some of the cardiovascular changes seen in endotoxic shock might be caused by this inability of the lung to metabolize PGF-2 $\alpha$, a PG with known pressor and venoconstrictor actions in most species although not the rabbit (see Karim \& Somers, 1972, for references). The reason for the different handling of PGE-2 and PGF-2 $\alpha$ by lung after endotoxin is not yet known.

We thank Dr John Pike (Upjohn Co.) for the gift of prostaglandins. This work was supported in part by W.H.O. contract S77121, and N.I.H. grant P30 HD10202 (Bioassay and Radioimmunoassay Cores). R.R.B was a W.H.O. Post-doctoral fellow.

\section{References}

Anderson, F.L., Jubicz, W., Tsagaris, T.J. \& Kuida, H. (1975) Endotoxin-induced prostaglandin $\mathrm{E}$ and $\mathrm{F}$ release in dogs. Am. J. Physiol. 228, $410-414$.

Anderson, F.L., Tsagaris, T.J., Jubicz, W. \& Kuida, H. (1975) Prostaglandin $F$ and $E$ levels during endotoxin-induced pulmonary hypertension in calves. Am. J. Physiol. 228, 1479-1482.

Änggärd, E. \& Samuelsson, B. (1964) Prostaglandins and related factors 28 . Metabolism of prostaglandin $\mathrm{E}_{1}$ in guinea-pig lung: the structure of two metabolites. J. biol. Chem. 239, 4097-4102.

Bhattacherjee, P. \& Phylactos, A. (1978) Depression of prostaglandin synthetase activity in kidney medulla by Shigella endotoxin injected intravenously. Biochem. Pharm. 17, 807-808.

Blackwell, G.J., Flower, R.J., Parsons, M.F. \& Vane, J.R. (1975a) Factors influencing prostaglandin turnover. Br. J. Pharmac. 53, 467P-468P.

Blackwell, G.J., Flower, R.J. \& Vane J.R. (1975b) Rapid reduction of prostaglandin 15-hydroxy dehydrogenase activity in rat tissues after treatment with protein synthesis inhibitors. Br.J. Pharmac. 55, 233238.

Blackwell, G.J., Flower, R.J. \& Herman, A.G. (1976) Effect of endotoxin on 15-hydroxyprostaglandin dehydrogenase in the rabbit jejunum and lung. Arch. Int. Pharmacodyn. 220, 325-326.

Bodkhe, R.R. \& Harper, M.J.K. (1979) Influence of hCG injection and steroid treatment on prostaglandin metabolism by rabbit uterus and oviduct. $J$. Reprod. Fert. 57, 101-112.

Dickson, W.M., Waldhaim, S.J. \& Amend, N. (1974) Blood flow to the oviduct of the non-pregnant rabbit. Biol. Reprod. 10, 335-345.

Harper, M.J.K. (1979) Prostaglandin (PG) production by rabbit oviduct. Proc. 4th Int. Prostaglandin Conference, Washington D.C. p. 46, Abstr.

Harper, M.J.K., Valenzuela, G. \& Hodgson, B.J. (1978) Accelerated ovum transport in rabbits induced by endotoxin. I. Changes in prostaglandin levels and reversal of endotoxin effect. Prostaglandins 15, 43-63.
Harper, M.J.K., Coons, L.W., Radicke, D.A., Hodgson, B.J. \& Valenzuela, G. (1979) Role of prostaglandins in contractile activity of the ampulla of the rabbit oviduct. Am. J. Physiol. (in press).

Herman, A.G. \& Vane, J.R. (1975a) Endotoxin and production of prostaglandins by the isolated rabbit jejunum. Influence of indomethacin. Arch. Int. Pharmacodyn. 213, 328-329.

Herman, A.G. \& Vane, J.R. (1975b) Increased prostaglandin production by tissue homogenates from endotoxin-pretreated rabbits. Proc. 6th Int. Congr. Pharmacology, Helsinki, p. 292, Abstr.

Herman, A.G. \& Vane, J.R. (1976) Release of renal prostaglandins during endotoxin-induced hypertension. Eur. J. Pharmac. 39, 79-90.

Hodgson, B.J., Harper, M.J.K. \& Valenzuela, G. (1978) Accelerated ovum transport in rabbits induced by endotoxin. II. Changes in oviductal smooth muscle activity. Prostaglandins 15, 65-79.

Karim, S.M.M. \& Sommers, K. (1972) Cardiovascular and renal actions of prostaglandins. In The Prostaglandins, Progress in Research, pp. 165-203. Ed. S. M. M. Karim. Wiley Interscience, New York.

Nakano, J. \& Prancan, A.V. (1973) Metabolic degradation of prostaglandin $\mathrm{E}_{1}$ in the lung and kidney of rats in endotoxin shock. Proc. Soc. exp. Biol. Med. 144, 506-508.

Ramwell, P.W., Fletcher, J.R. \& Flamenbaum, W.F. (1975) The arachidonic acid-prostaglandin system in endotoxemia. Proc. 6th Int. Congr. Pharmacology, Helsinki, Vol. 5, pp. 175-182.

Sokal, R.R. \& Rohlf, F.J. (1969) Biometry, p. 239. W. H. Freeman and Co., San Francisco.

Spilman, C.H. \& Harper, M.J.K. (1973) Effect of prostaglandins on oviduct motility in estrous rabbits. Biol. Reprod. 9, 36-45.

Valenzuela, G. \& Harper, M.J.K. (1976) Effect of estrogen on activity of prostaglandin synthetase in rabbit oviduct. Prostaglandins 12, 535-549.

Received 27 March 1979 